\title{
Museums and the Shaping of Contemporary Artworks
}

\author{
Sherri Irvin
}

sirvin@ou.edu

Please cite the published version, in Museum Management and Curatorship 21 (2006), 143-156.

\begin{abstract}
:
In the museum context, curators and conservators often play a role in shaping the nature of contemporary artworks. Before, during and after the acquisition of an art object, curators and conservators engage in dialogue with the artist about how the object should be exhibited and conserved. As a part of this dialogue, the artist may express specifications for the display and conservation of the object, thereby fixing characteristics of the artwork that were previously left open. This process can make a significant difference to the visual appearance of the work, the nature of the audience's experience, and how the work should be interpreted. I present several case studies in which the nature of the artwork has been shaped by such dialogues, and discuss principles for resolving cases in which there is a conflict between instructions specified by the artist and those adopted by the museum.
\end{abstract}

\section{Key words:}

contemporary art, installation, conservation, philosophy of art

What exactly does a museum acquire when it purchases a contemporary artwork? Sometimes, the acquisition is mostly immaterial: some artworks, like Jana Sterbak's Vanitas: Flesh Dress for an Albino Anorectic, a dress sewn of pieces of flank steak and allowed to desiccate over the course of the exhibition, involve very few enduring physical components. ${ }^{1}$ But even when the acquisition is primarily of one or more physical objects, the objects on their own often are not sufficient to constitute the work. When the National Gallery of Canada purchased Liz Magor's 1980 work Production, it acquired 2800 bricks Magor had made out of newspaper, along with the press she used to make them. [INSERT FIG. 1 HERE] But the work is not simply the bricks and the press: to constitute the work, those objects must be installed in an acceptable configuration. Many of the standards for acceptable installation developed in negotiations with Magor and curators and conservators after the artwork was acquired by the museum. In a fax to a curator regarding installation, Magor stated,

Yes, there are a thousand different ways to do it. But there's a notion or rule of thumb that eliminates some of them and modifies the others. I like it best when the bricks are trying to act architecturally -

\footnotetext{
${ }^{1}$ The dress is exhibited on a mannequin stand which, unlike the dress itself, is
} preserved from one exhibition to the next. 
they're trying to make a wall or a column or something. The ultimate would be that they totally cover a wall, with no space at the top, bottom or sides.... (Magor unpublished-b)

The work, then, is not simply the bricks and the press, but the bricks and press installed in accordance with the standards the artist has indicated.

Moreover, in response to another curator's query about care of the bricks, Magor made clear that the particular bricks she delivered to the museum are not essential to the work. (Magor unpublished-a) She supplied detailed instructions for making new bricks, given that the bricks she made from newspaper may deteriorate over time.

Through these communications with the museum and its representatives, Magor determined some of the features of the artwork: namely, that the bricks should be installed in accordance with certain principles, and that the bricks Magor herself created are replaceable components. The artist's artmaking activity, then, goes beyond the making or assembling of a set of physical objects: it extends also to certain aspects of the artist's relationship with curators, conservators and other agents of the institution that acquires the work. When the artist supplies a set of instructions for installation, this is part of what makes the artwork what it is. I have elsewhere referred to this as the artist's sanctioning of features of the work (Irvin, 2005). The artist's sanction is the determination of features of the artwork through the artist's actions or communications. The most familiar way for an artist to sanction features of the artwork is by conceiving of and making an object: when the artist places paint on a canvas in a particular configuration, the artist is sanctioning a set of visible characteristics of the artwork. But in addition to making objects, artists typically present those objects, in many cases both for exhibition and for sale. This involves communicating with buyers and exhibiting institutions in a way that may generate sanctions of further features of the work.

In the case of Liz Magor, through her communication with curators the artist has sanctioned certain configurations for display, ruled out others, and expressed principles for generating further acceptable configurations. She has also sanctioned the replaceability of the particular bricks she made. The acceptability of a certain range of configurations, and the replaceability of the bricks, are features of the artwork that were established by the artist's sanction when she communicated them clearly to the institution. And a full understanding of the work will include an awareness of such features: through the replaceability of the bricks, and the possibility of installing them in different configurations, this work makes reference to the real world of production, in which modular, interchangeable components are essentially amenable to being assembled to form a variety of different structures. The reference to real-world practices of construction is relevant to interpretation of the work: it opens up possibilities for seeing the work as social commentary that would be closed if the bricks were always used to generate the same static structure. If the work were always installed the same way, 
viewers would not be pressed to reflect on the relationship of individual components to the final, overarching structure, or on the way that workers' labor is a crucial precursor to more "elevated" creative activities like design and architecture. The artist's sanction, then, determines features of the artwork in a way that is highly relevant to interpretation of the work.

So far, I have focused on the artist's role: it is what the artist says and does that results in the sanctioning of certain features of the work. But insofar as curators and conservators often initiate and participate actively in the dialogues within which such sanctions are created, they, and the museums they represent, may play a central role in shaping the nature of the artwork. Had a curator never contacted Magor to request further guidelines for installation, the artist might never have expressed her preference that the bricks "act architecturally". Had a curator not requested instructions for the care of the bricks, the artist might never have indicated that she did not consider the particular bricks she made to be essential to the work. The way that the work is to be installed, and the possibility of replacing the original bricks with new ones, are important features of the work, which are relevant to interpretation. Although the artist is responsible for sanctioning these features, it is important to note that the artist did so, in this case, only as a result of dialogues in which museum curators were crucial participants. The museum and its agents may play a central causal role in the generation of sanctions, and thus in the determination of features of the work. ${ }^{2}$

Anyone familiar with the exhibition of contemporary artworks is likely to recognize this pattern of events: curators initiate contact with the artist to establish standards for display and conservation, and the negotiations typically happen in a cooperative and collaborative spirit, in which both parties try to find ways to respect the integrity of the work within a diverse set of museum constraints which may pertain to budget, visitor safety and the need to preserve the acquired objects. Conservators often participate actively in this process: at the National Gallery of Canada, for instance, it is the Conservator of Contemporary Art who, in the process of writing a report on each work that is under consideration for acquisition, works with the artist to establish standards for display and conservation. In some cases, the conservator's record-keeping must be exquisitely detailed, particularly when the institution, in installing the work, is responsible for constituting many of its aesthetic qualities.

${ }^{2}$ An anonymous reviewer has pointed out the irony of the fact that installation artworks, which grew out of a movement toward ephemeral art that was largely antiinstitutional in orientation, should now be so thoroughly integrated into the institutional context that we must speak of institutions as playing a role in the determination of their features. While it would be interesting to trace the historical developments that led to this situation, for the present I will restrict my discussion to the more pragmatic aim of ascertaining how we should understand and treat the works given that they are now in an institutional context. It is perhaps important to note that most of the works I discuss seem to draw as much from a strong sculptural tradition as from a movement characterized by anti-institutional ephemerality. 
One example is Stephen Schofield's A raging stream is called violent but not the riverbed that hems it in (1991-1992). [INSERT FIG. 2 HERE] This work consists of several pieces of found office furniture, each with a slab of plaster on top. On each piece of furniture, a truncated humanoid figure, with no head, hands or lower body, is slouched. The figures are made out of grey fabric (mostly silk organza), sewn to the pattern of a boy's shirt. They are then filled with sand and positioned on the pieces of furniture. The figures are emptied and the sand discarded between exhibitions, so each time the work is shown the figures must be carefully refilled and correctly positioned on the furniture. The conservator's report on the work includes detailed instructions for filling and positioning each figure. For one of the figures, called "Flood," the instructions say, "Slight shaping of the sand arrangement within the torso part is done in such a way as [to suggest] slight depression on both top side[s] like the small of the back." The conservator also notes, Documentation is essential for this work since [the] method of filling and installing each shirt over its base or mount is unique for each of them and impl[ies] all sorts of subtle effects. It is imperative for each of the components of this work to be well photo-documented in order to be able to achieve the artist's intention for display. (Gagnier unpublished-b)

In such cases, the artist's interaction with the conservator serves to specify which observable features of the objects are essential to the work, and which (if any) are merely contingent. In indicating these details to the conservator, who then incorporates them into the official institutional policy with regard to display of the work, the artist sanctions certain features of the work.

Of course, a number of complications may arise within this process. Instructions may be mis-transcribed, or important details may be omitted. Instructions that have been recorded accurately may be incorrectly executed. Or, in perhaps the most difficult sort of case, the interests of the institution in such things as preserving the objects and protecting viewers may come into conflict with the artist's instructions. What should we say about cases in which the museum exhibits the work in a way that does not coincide with the features sanctioned by the artist? As we will see, violating the artist's sanction may sometimes be justified, but this should be done only for compelling reasons, and typically the violation should be compensated for by providing information to the audience about how their experience of the work differs from the experience they would have had if the artist's sanction had been adhered to.

Jamelie Hassan's 1981 work Los Desaparecidos is made up of 74 porcelain pieces that are displayed on the floor, along with a photocopied dossier containing information about missing Argentineans, who are believed to have been murdered by the military junta in power from 1976 to 1981 . After the National Gallery of Canada acquired and exhibited the work, the artist wrote to a curator to supply instructions for installation, since she had found the initial installation to be "somewhat cramped". (Hassan unpublished-b) 
[INSERT FIG. 3 HERE] The new instructions sent by the artist included both text and a drawing; in particular, she indicated that the pieces of porcelain should be placed so as to allow "enough room to move around and throughout the pieces. As a guide to measure ... distance from the adjacent walls and between each piece a foot step between is appropriate.... Positioning the piece in this way allows for physical accessibility into the work." (Hassan unpublished-a) In the drawing, she has placed arrows between some of the porcelain pieces, presumably illustrating her instruction that enough space should be left for the viewer to step between them. Her drawing also shows the dossier placed very close to the porcelain pieces; since the dossier is to be handled by the viewer, this placement might well encourage people to move through the piece. Hassan even suggests, "Perhaps a note of explanation that the dossier can be handled and read would help in breaking down the intimidation set up by the 'do not touch' approach of an institution." (Hassan unpublished-a)

Based in part on the drawing and instructions supplied by the artist, conservator Richard Gagnier of the National Gallery of Canada generated a new drawing and set of installation instructions for a particular exhibition of the work. [INSERT FIG. 4 HERE] These instructions include the following: A walk way is provided all around the work by allowing about $80 \mathrm{~cm}$ in between the wall and the pieces.... Distance in between the pieces within the triangle is about 15 to $20 \mathrm{~cm}$, providing a fair amount of space in between them yet not enough to encourage [the] viewer to walk within the grouping for protection of the porcelain objects. (Gagnier unpublished-a)

The conservator also adds:

When selecting the porcelain pieces for the side edges, try to choose the ones that [offer] a more flat or compact appearance leaving the ones with raised floating fold corner[s] for the interior arrangement as they are prone to multiple breaks if hurt by [the] viewer by accident. (Gagnier unpublished-a)

The National Gallery of Canada's curatorial dossier for this work also contains photographic documentation of such breakage. Finally, in the conservator's drawing, unlike the artist's, very little space seems to be allowed between the porcelain pieces, but considerable space is left between the dossier and the pieces. This has two effects: it cleanly and aesthetically frames the dossier, rather than integrating it with the disarray of the other elements, and it discourages the viewer from believing that his or her access to the dossier should be translated into access to the porcelain pieces themselves.

The conservator's installation instructions depart from the artist's sanction in at least two ways. First, the conservator adds an element on which the artist is silent: he advocates placing the flatter porcelain pieces around the perimeter of the installation, whereas the artist's drawing seems to indicate a more random array, with both flat and curved pieces interspersed. Second, he is explicit in allowing less space between the pieces precisely to discourage viewer access to the interior of the work. [INSERT FIG. 5 
HERE] It is clear that the work installed in accordance with the conservator's instructions will be aesthetically different from the work installed in accordance with the artist's instructions and diagram. The work will look different: with less space between the pieces, the installation will be more compact; and with the dossier framed by empty space, it will be neater.

Moreover, these differences will, as the conservator predicts, have an effect on the viewer's relationship to the work. The artist proposes the assembly of objects as something in which viewers can immerse themselves, and with which they can interact intimately. By walking among the pieces, a viewer is surrounded by them and experiences their fragility, as well as her own power to damage them and responsibility not to. Because they are still very much present in her field of vision as she consults the dossier, the elements of fragmentation and fragility are perhaps more present to her thoughts as she looks over the pictures and notes in Spanish about those who have disappeared.

The experience available from an installation in accordance with the conservator's instructions is rather different. The viewer experiences herself as distanced from the piece rather than immersed in it. The piece does not invite her to enter and immerse herself within it; instead, its very configuration becomes a subtle expression of the institutional conventions that serve to control viewers by creating a buffer zone that discourages contact. The piece thus becomes part of an institutional framework in which viewers are seen as posing a threat to artworks, which must be protected from them. Hassan, the artist, is quite aware of the fact that the work's very placement within a museum carries the danger of causing viewers to feel distanced and controlled, which is why, as discussed above, she suggests including a note that says the dossier may be handled to "help in breaking down the intimidation set up by the 'do not touch' approach of an institution."

The factor of institutional intimidation and exclusion is crucially important here, of course, since the piece is all about intimidation and control of a population by its government. When the viewer's experience of the piece is, even subconsciously, one of being controlled and excluded, this becomes interpretatively relevant; the artwork, rather than seeming to be a vulnerable individual response to a situation of intimidation and coercion, which the viewer is invited to share in, becomes the expression of an institutional agenda which, while comparatively benign, is still one in relation to which individuals are largely powerless.

The artist has clearly sanctioned certain aspects of the installation of the piece, and an installation in accordance with the conservator's instructions will violate that sanction in certain respects. This means that the work will be mis-presented: it will not possess the attributes that the artist sanctioned for it, and thus viewers will be misled, to some degree, about the work's 
nature. This, in turn, is likely to lead to misinterpretation, unless the institution does something to inform viewers about the ways in which their experience of the piece fails to duplicate that sanctioned by the artist.

But should we condemn the institution for failing to present the work in accordance with the artist's sanction, or the conservator for generating instructions that conflict, in some ways, with those supplied by the artist? To answer this question, it is important to note that the generation of explicit instructions is not the only way in which an artist sanctions features of her work. Selling the work into the collection of a major museum, with its established policies and conventions, is itself an act of presentation which affects what the artist has sanctioned. For example, when a painter sells a work to a museum with the policy of maintaining paintings in the state they were in at acquisition, he has implicitly sanctioned that his own painting will be treated in accordance with this policy (unless he does something explicitly to indicate that this policy should not be applied). Similarly, when Hassan sold her work to the National Gallery of Canada she relinquished it to an institution with a clear mandate to maintain the physical integrity of the artifacts under its care. She thus implicitly sanctioned that the porcelain objects should be maintained in an unbroken state (and that measures should be taken so to maintain them). ${ }^{3}$

Thus, we have an explicit sanction, that viewers be permitted to walk among the pieces, and an implicit sanction, that the physical integrity of the pieces be maintained. There is nothing internally contradictory or incoherent about this pair of sanctions; if viewers could be counted on to be very careful, it would be possible to respect the two sanctions simultaneously. Given the real-world situation of a public museum, however, in which audiences and objects often collide, it is unreasonable to expect that the pieces will be maintained unbroken in a situation where viewers are allowed to circulate within the work: as mentioned earlier, instances of damage to the porcelain pieces due to viewer contact have already been documented.

The museum, then, is faced with the necessity of deciding how to present the work in a way that preserves its integrity to the greatest possible degree while conflicting with something the artist has sanctioned. At first glance, it might seem clear that when tension arises between them, the artist's explicit sanction should take precedence over the implicit sanction: and so viewers should be allowed to circulate among the porcelain pieces regardless of the consequences.

However, if Hassan had regarded the integrity of the porcelain pieces as unimportant, or had thought of them as replaceable, it was open to her to communicate this to the National Gallery of Canada, and perhaps to supply a set of replacement objects. In failing to do so, she left intact the conventional assumption that the appearance and integrity of the objects

${ }^{3}$ For more on the notion of implicit sanctions, see Irvin (2005). 
created by the artist are important and to be preserved in the long term, for future generations of viewers.

Hassan thus did not exercise certain options that were open to her, if she wished to create a sanction that would exempt her work from the National Gallery of Canada's conservation policies. Now, one might wish that curators or conservators from the National Gallery had contacted her, giving her the opportunity to resolve the tension by creating a new sanction. ${ }^{4}$ But in the absence of additional communication from the artist, the museum's representatives are charged with deciding how to present the work given a diverse array of considerations. It seems crucial to recognize that the museum, and particularly the conservator, has a legitimate interest in preserving the artifacts under its care. Among the raisons d'être of an art museum is the safeguarding of valuable artworks so that they can be experienced by future viewers, perhaps over a period of hundreds of years. Artists are familiar with this institutional role when they sell their works into museum collections. Moreover, it is clear that, in the case of Los Desaparecidos, the museum's interest (which is also the present and future audience's interest) in preserving the artifacts Hassan produced comes into conflict with the artist's explicit sanction of viewer interaction with the objects. The ensuing damage, if extensive, may seriously compromise the experience available to future viewers, since even with superior conservation efforts cracks and gaps may, over time, come to be visible in the surface of objects to which multiple repairs have been made. Since Hassan has never indicated that she sees breakage of the pieces as a feature of the work that should be accepted and incorporated into it, the work must be understood as consisting of the pieces in the original, undamaged state in which she initially presented them. The best way for the museum to discharge its obligation with respect to the integrity of the work (an obligation that stems in part from Hassan's implicit sanctioning of the intact state of the objects she made), then, is to take special measures to prevent damage to the porcelain pieces.

\footnotetext{
${ }^{4}$ Were Hassan to proffer a solution in response to a conservator's query, she would be instituting a new sanction and thus changing the work. There is thus nothing in the nature of the work itself that requires that the solution come from the artist rather than from within the institution; a preference for asking the artist to change the work in this situation must come from ethical or aesthetic considerations independent of the nature of the particular work the artist has already created. Contacting the artist has potential drawbacks to which the museum may be sensitive: if the artist were to sanction that the porcelain pieces should simply be allowed to disintegrate as a result of viewer contact, this would alter the work, and the museum might not wish to have this new version of the work in its collection. While (as discussed below) the museum is within its rights to reject the new version of a work that is generated when an artist issues a new sanction after acquisition is complete, to do so might well compromise the relationship between the artist and the institution. As my concern here is with the nature of the work, and with how it should be exhibited given its nature, I will not weigh in on the question whether, in this situation, an artist-initiated change in the work should be sought.
} 
Thus we should not hold that the museum has an absolute obligation to exhibit the work in a way that accords with the explicit artist's sanction: if doing so results in damage to the objects which the artist has not explicitly sanctioned, future viewers may lose the possibility of encountering the work at all, or their experience of it may be even further from that sanctioned by the artist. But when violating some aspect of the artist's sanction is necessary to protect the artifacts, the institution can and should take steps to ensure that the ensuing misunderstanding of the work is minimized. What guidelines are to be followed in minimizing this misunderstanding? The artwork, as sanctioned by the artist, makes a certain kind of experience available to the viewer. When the work is presented in a way that does not fully correspond to the artist's sanction, this experience is altered. What the institution should aim to do, then, is present the work in a way that provides the viewer with an experience that is as close as possible to that provided by the work as sanctioned by the artist; and where these experiences diverge, audience members should be made aware of this and provided, where possible, with the information required to imaginatively reconstruct the experience of the work as sanctioned by the artist. ${ }^{5}$

In the case of Los Desaparecidos, the institution might fulfill this obligation by providing a wall text indicating that the artist meant for audience members to be able to circulate among the porcelain pieces. Perhaps even a video presentation of the work as seen from the point of view of a spectator walking among the pieces would be helpful. Of course, the experience viewers will have upon reading such a wall text or viewing such a video presentation will differ considerably from the experience of walking among the pieces. And inevitably, some of their attention will be drawn to the fact that the museum is precluding them from having a full experience of the work as sanctioned by the artist. But at least, given these remedies, viewers will be able to construct a better understanding of the work, as they recognize that it is not entirely aligned with the agenda of the institution that houses it.

The suggestions I have offered in relation to this particular piece are tentative, and further reflection on how best to present the work is certainly warranted. Among the considerations that should come into play are those of how to convey the relevant information about the artist's sanction without being too heavy-handed, and how to encourage viewers to imaginatively reconstruct the experience of the work as sanctioned by the artist without leading them to physically pursue that experience, which would jeopardize the objects. Museum curators and conservators who routinely deal with the public are probably in the best position to generate proposals that strike a

\footnotetext{
${ }^{5}$ Similar considerations apply to the migration of media works from one medium to another in response to changes in technology: where presentation of the work in the original medium is not possible, curators and conservators should be guided by the idea of providing an experience as close as possible to that made available by the work as originally sanctioned.
} 
balance among the various competing considerations while promoting satisfying viewer experiences and respecting the integrity of the work.

As we can see from the above cases, the museum often welcomes the artist's participation in establishing standards for display of the artwork; and even when the artist's explicit sanction is not fully adhered to, the museum does its best to convey the spirit of the artist's work within the constraints imposed by its institutional role. Even in the case of Los Desaparecidos, the museum's failure to present the work in accord with the artist's sanction was not a function of disagreement with the artist about the nature of the work, but rather of the need to consider the future integrity of the objects so that the work's nature could be preserved in the long term.

However, occasionally another sort of case arises, in which the artist attempts to alter the nature of the work after the museum has acquired it, but the museum does not welcome this intervention. Jana Sterbak's 1984-5 I Want You to Feel the Way I Do ... (The Dress) is such a case. [INSERT FIG. 6 HERE] The work, as initially acquired by the National Gallery of Canada, is a dress made of wire mesh, displayed in a darkened room. When a viewer enters the room, a motion detector activates the slide projection of a text on the wall behind the dress, and also activates a heating element in the dress, causing it to glow. The text reads as follows:

I want you to feel the way I do. There's barbed wire wrapped all around my head and my skin grates on my flesh from the inside. How can you be so comfortable only 5" to the left of me? I don't want to hear myself think, feel myself move. It's not that I want to be numb, I want to slip under your skin: I will listen for the sound you hear, feed on your thought, wear your clothes.

Now I have your attitude and you're not comfortable anymore. Making them yours you relieved me of my opinions, habits, impulses. I should be grateful but instead ... you're beginning to irritate me: I am not going to live with myself inside your body, and I would rather practice being new on someone else.

Since the National Gallery of Canada acquired the work, the artist's conception of how it should be displayed has changed. The work has often been lent out for exhibition, and typically both the Conservator of Contemporary Art and the artist have been present for the installation. The artist has over time come to reject the projection of the text onto the wall behind the work, and now prefers that the text be printed on the wall or on a card instead. However, it is the National Gallery's position that a change in the display undermines the work they initially acquired. The conservator has told me that he knows of cases in which he supervised the installation of the work in accordance with the National Gallery's exhibition standard, but after his departure the artist instructed the exhibition venue to remove the projection. ${ }^{6}$

${ }^{6}$ Conversation with Richard Gagnier, April 28, 2005. 
Should the museum accede to the artist's desire to change the way in which the work is displayed? Is a refusal to do so simply arbitrary? In 1997, the Curator of Contemporary Art, Diana Nemiroff, wrote to the artist both to assert the legitimacy of the National Gallery of Canada's position and to explain the reasons underlying it.

While it is not completely out of the question to make changes to a work that no longer belongs to you (particularly if the changes do not mean that it becomes impossible to show the work as originally conceived), this should only be done with the clear, written consent of the owner....

The curator mentions a technical difficulty with removing the projection, but goes on to say:

However, more important here are the aesthetic and "moral rights" issues. [The slide-projected text] adds an important and provocative layer to the work, both through the words themselves and through their "projection," which mimics the psychological projection of the subject of the narrative. Printed words on a card do not do this. And I would argue further that the text works best when most closely integrated with the dress by being projected on the wall behind it, as it was originally. (Nemiroff, unpublished)

The curator concludes by indicating that the National Gallery of Canada will continue to regard the slide projection as "an integral part of the work which must be respected" for the purpose of exhibition and loan. The museum has, however, gone some distance toward accommodating the artist: on its web site, the image has been changed to reflect the artist's preference; the text is simply printed on the web page, rather than included in the image of the work. ${ }^{7}$ The description of the medium, however, continues to state that the slide projection is part of the work.

Is the museum acting appropriately in preventing the artist from effecting a change in the work, based on the curator's judgment that the work's quality would be compromised by the change? Consideration of artworks in traditional mediums suggests that this is perfectly acceptable. There is no expectation that a painter will be permitted to repaint his work once it has been acquired by a museum; and, in my view, an artist's changing the standards that she has sanctioned for the work's exhibition is much like repainting the surface of a canvas: it really does constitute a change in the work's nature. If the museum's representatives thought that the change would improve the work, they might have no reason to resist it; this would involve the museum's coming to own a different version of the piece than it initially acquired. ${ }^{8}$ If Jamelie Hassan, in the case of Los Desaparecidos, were

\footnotetext{
7 See http://cybermuse.gallery.ca. This description of the page is accurate as of February 22, 2006.

${ }^{8}$ Of course, the interest in maintaining a collection that is historically representative might give the institution a reason to resist even changes that are thought to improve the work aesthetically. Sterbak's resistance to the projected text may be due to the fact that it has come to seem dated or overbearing; but this may be a
} 
to endorse the mode of display recommended by the curator, then this would, in effect, amount to her creation of a newer version of her work, and the museum could display it accordingly without further concern that the work is being mis-presented. Thus the museum is free to invite or permit artists to modify their works after acquisition, but is, as far as I can see, under no obligation to do so.

I do think, however, that we should say that Jana Sterbak has, in fact, created a new version of her work, a version in which the dress is not accompanied by a slide projection. This is somewhat as if a writer were to create a new version of a poem, retaining much of the original material but incorporating new material within it; or as if a sculptor were to disassemble a complicated piece and reconstitute it in a different arrangement, without considering this to be simply an alternate configuration of the original work. The fact that Sterbak no longer owns the dress component of the work does not strike me as a necessary barrier to her creating a new version of the work that includes it, since she retains intellectual (though not physical) property rights in relation to it. Thus, Sterbak has created a new version, but the National Gallery of Canada owns only the earlier version, which it has elected not to trade in. Another exhibition venue, then, could, as far as the authenticity of the work is concerned, legitimately choose to show the later version, which Sterbak prefers. But it does seem that they would be violating their obligations to the lending institution, unless permission were granted for what is, from the perspective of the National Gallery of Canada, an unorthodox display. Thus the artist has created two versions of her work; but because she no longer owns the physical components of the work, it may be up to interinstitutional negotiation to determine whether the more recent version can ever legitimately be shown.

The museum, then, can contribute to the constitution of the artwork, and can also play a very significant role in determining whether what the viewer sees corresponds to the work the artist has sanctioned. There are certainly cases in which it is legitimate for the museum's display to diverge from the artist's sanction, as in Los Desaparecidos; but in such cases, the museum should do what it can to help viewers imaginatively reconstitute the experience they would have had if the work had been presented in accordance with the artist's sanction. Finally, the museum cannot prevent the artist from changing the features she sanctions for the work; but it can choose to maintain the original version in its collection, just as we may prefer the earlier version of a poem to the later. These decisions should be taken with caution, given that artists tend to be experts on the aesthetic value of their work. Perhaps Jana Sterbak is right about the projection; it does seem a bit overbearing, especially given the content of the text. But museums should

reason to maintain it, if it contributes to making the work well-suited to represent the mid-1980s in the museum's collection. 
be free to accept or refuse such alterations: ${ }^{9}$ in agreeing to the transaction in which the work passes from the artist's hands into the museum's collection, the artist has declared the work finished, and relinquishes her right to tinker with the objects without the museum's permission. In at least some cases, this may provide a degree of aesthetic protection for works and their viewers: after all, it's not inconceivable that an artist, through continued meddling, could make the artwork worse rather than better.

\section{Acknowledgements:}

I gratefully acknowledge the financial support of the Social Sciences and Humanities Research Council of Canada, research assistance provided by April Britski, and access to National Gallery of Canada files provided by Richard Gagnier and Jane Robertson. I am grateful to Jamelie Hassan, Richard Gagnier, Liz Magor and Diana Nemiroff for permission to quote from their memos and correspondence. Permission to reproduce images of their work was graciously provided by Jamelie Hassan, Liz Magor, Stephen Schofield and Jana Sterbak.

\section{References:}

Gagnier, Richard (unpublished-a). Installation Notes - Survey Results Show, undated memo.

Gagnier, Richard (unpublished-b). Consideration Prior to Acquisition, Restoration and Conservation Laboratory Report for Stephen Schofield's $A$ raging stream is called violent but not the riverbed that hems it in, May 12, 1997.

Hassan, Jamelie (unpublished-a). Desaparecidos: Instructions for Installation, memo dated October, 1983.

Hassan, Jamelie (unpublished-b). Letter to Jessica Bradley, October 19, 1983.

Irvin, S. (2005). The artist's sanction in contemporary art. Journal of Aesthetics and Art Criticism 63, 315-326.

Magor, Liz (unpublished-a). Letter to National Gallery of Canada conservators, August 23, 1985.

\footnotetext{
${ }^{9}$ An important thing to note, however, is that the museum is not free to pick and choose, accepting some changes proposed by the artist and rejecting others. Works, and versions thereof, are packages: the museum can legitimately display only a whole package sanctioned by the artist. A hybrid of two versions of a work is not itself a legitimate version unless the artist sanctions it. A case in which a museum chooses to display a hybrid that has not been sanctioned by the artist should be treated as a case in which it is displaying one of the sanctioned versions of the work, and violating some of the artist's particular sanctions with respect to that version.
} 
Magor, Liz (unpublished-b). Fax communication to Germaine Koh, November 25, 1998.

Nemiroff, Diana (unpublished). Letter to Jana Sterbak, November 26, 1997.

Figure captions:

Fig. 1: Liz Magor, Production (1980). National Gallery of Canada, Ottawa. Purchased 1984.

Fig. 2: Stephen Schofield, A raging stream is called violent but not the riverbed that hems it in (1991-2). National Gallery of Canada, Ottawa. Purchased 1997.

Fig. 3: Jamelie Hassan, drawing accompanying installation instructions for Los Desaparecidos, dated October, 1983.

Fig. 4: Richard Gagnier, drawing accompanying installation instructions for Jamelie Hassan's Los Desaparecidos, undated.

Fig. 5: Jamelie Hassan, Los Desaparecidos (1981). National Gallery of Canada, Ottawa. Purchased 1983.

Fig. 6: Jana Sterbak, I Want You to Feel the Way I Do ... (The Dress) (19845). National Gallery of Canada, Ottawa. Purchased 1986.

\section{Biography:}

Sherri Irvin is Assistant Professor of Philosophy at the University of Oklahoma. She received her Ph.D. in philosophy from Princeton University in 2003. She has worked at and served on the administrative boards of nonprofit galleries in Canada, has curated an exhibition, and has written for Canadian art magazines. Her philosophical articles have appeared in the British Journal of Aesthetics and the Journal of Aesthetics and Art Criticism. 